\title{
DE NOME A PRONOME: UM ESTUDO SOBRE O ITEM SENHOR
}

\begin{abstract}
Jânia Martins Ramos*
Resumo: Adotando a concepção formalista de gramaticalização, as diferentes realizações do item senbor foram descritas neste artigo como um processo resultante da recategorização de um nome. No eixo diacrônico, foi identificado o seguinte percurso no que diz respeito à posição estrutural de senhor: adjunto > especificador $>$ núcleo. É na posição de vocativo que senbor ocorre como nome nu. Este teria sido o gatilho da reanálise nome $>$ pronome ou, mais exatamente, $\mathrm{N}>\mathrm{D}$.

Palavras-chave: Gramaticalização; pronominalização; senbor.

Abstract: The formalist concept of grammaticalization was adopted in this article in order to describe the different realizations of the item senbor ("sir") from Brazilian Portuguese as the resulting process of a recategorization of a noun. It was identified the following diachronic path of this item as far as its structural position is concerned: adjunct $>$ specifier $>$ head. It is in the vocative position that the item senbor occurs as a bare noun. This would be the trigger for a reanalysis of the noun $>$ pronoun or, more exactly, $\mathrm{N}>\mathrm{D}$.
\end{abstract}

Keywords: Grammaticalization; pronominalization; senbor.

* Universidade Federal de Minas Gerais / CNPq. 


\section{Observações preliminares}

Não é incomum nas línguas, nomes e expressões nominais adquirirem características de pronomes. Análises tipológicas identificam uma hierarquia em relação aos nomes: nomes $>$ nome pronominalizado $>$ pronome $>$ pronome pessoal (HEAD, 1978). Já no âmbito dos estudos sobre gramaticalização que assumem um enfoque minimalista, o processo que leva à formação de pronomes é um processo de mudança sintática, que envolve a criação de novo material funcional através de reanálise, resultando sempre em simplificação estrutural (ROBERTS \& ROUSSOU, 2003).

Neste artigo, adotamos a concepção de pronomes como feixe de traços (HARLEY \& RITTER, 2002; CARVALHO, 2008). Assim a diferença entre os itens que aparecem na hierarquia acima difeririam entre si em termos dos traços neles contidos. Nesta perspectiva, a pronominalização seria descrita como reanálises que levam à perda de traços. A noção de perda ficará mais clara no decorrer do artigo. Nosso objeto de estudo é a cline (1) abaixo, ${ }^{1}$ diacronicamente documentada no português:

(1) $\operatorname{senhor}>\ldots>\operatorname{sinhô}>\ldots>$ sô

Nosso objetivo é mostrar que senbor e sô são pronomes, sendo o primeiro uma forma homônima de um nome. Nossa discussão neste texto está dividida basicamente em quatro seções. Na primeira, será feita uma breve revisão da literatura sobre estatuto gramatical do item senbor. Na segunda seção, define-se pronome, adotando-se uma abordagem formalista (POSTAL, 1969; SIEWIERSKA, 2004; GELDEREN, 2004, 2006). Na terceira seção, são apresentados resultados de análise de quatro corpora de língua portuguesa: três diacrônicos e um sincrônico. Na quarta seção, faz-se uma análise formal dos dados, em que se argumenta a favor da atuação do princípio Head Preference Principle - HPP (GELDEREN, 2006).

\footnotetext{
${ }^{1} \mathrm{O}$ número de realizações fonológicas é muito maior que o apresentado. Em vista disso, foram usadas reticências a fim de deixar claro que há lacunas nesta descrição.
} 


\section{O item senbor no português}

Head (1976, p. 185) classifica senhor como "nome altamente pronominalizado", o que lhe asseguraria o segundo nível na escala nomes $>$ nome pronominalizado $>$ pronome $>$ pronome pessoal. Veja-se que Head acrescenta o advérbio "altamente". Tal descrição acarreta que ser pronome não é um estágio alcançável abruptamente, mas um estágio a ser alcançado gradualmente, podendo haver itens muito ou pouco pronominalizados. Ilari, Franchi, Neves \& Possenti (1996, p. 89, negrito nosso) afirmam que "talvez o nosso quadro de pronomes pessoais em português devesse incluir, na segunda pessoa, o senhor / a senbora".

Como se pode ver, diferentes autores reconhecem traços pronominais no item senbor, embora ainda restem dúvidas quanto a seu estatuto de pronome pessoal. Entretanto, são unânimes em reconhecer que haveria um processo de pronominalização em relação a esse item, sem, entretanto, explicitar o processo.

No português brasileiro (PB) atual senhor é um pronome de segunda pessoa. Uma evidência disso são diálogos, como em (2) abaixo. Aqui "a entidade de seu referente pode somente ser determinada pelo contexto linguístico" (SIEWIERSKA, 2004, p. 9; tradução nossa). Essa dependência referencial seria a única relevante na identificação de pronomes, conforme Noguchi (1997) e Bresnan (2001b).

(2) A: - Posso me assentar ali?

B': - Sim, o senhor pode se assentar ali.

B": - *Sim, um senhor pode se assentar ali.

B"”: - *O bom senhor pode se assentar ali. ${ }^{2}$

Nas respostas em (2), o item senhor refere-se àquele que faz a pergunta e apenas o contexto extralinguístico permite identificar

\footnotetext{
${ }^{2}$ Indicamos aqui a agramaticalidade de uma sentença com um asterisco e a dúvida sobre sua agramaticalidade com asterisco seguido de interrogação.
} 
quem ele é. Veja-se que em (B") senhor vem precedido de um artigo indefinido e em (B"') de um adjunto. O resultado, em ambos, é a impossibilidade de senhor referir-se a quem faz a pergunta. Em outras palavras, apenas com a presença de um artigo definido a sequência constitui resposta adequada à pergunta (A).

Consideremos agora a forma fonologicamente reduzida, sô, inserida nas respostas à pergunta (A) abaixo:

(3) A: - Posso me assentar ali?

B': - Sim, sô pode se assentar ali.

B": - *?Sim, o sô pode se assentar ali.

B"': - *Sim, um sô pode se assentar ali.

B"'”: - *O bom sô pode se assentar ali.

A comparação dos diálogos (2) e (3) permitem verificar que a forma reduzida não aceita artigo definido, enquanto a forma plena o aceita. Isso constitui uma indicação de que o item pleno seria estruturalmente mais complexo do que o item reduzido. Tal descrição nos remete ao processo de gramaticalização, conforme se verá na seção a seguir.

Ao lado de $s \hat{o}$, outras formas foneticamente realizadas são documentadas por diversos autores. Biderman (1973, p. 370), a partir de um corpus formado por obras literárias dos sécs. XVIII, XIX e XX, identifica "a coexistência de corruptelas e variantes, apontando as ocorrências siô, nhôr, nhozinbo, nhonbô, nhô, sô, seu e sinbô". Amaral (1982, p. 195), por sua vez, aponta formas no masculino e no feminino, indicando serem sempre proclíticas a nomes: $n h o$, seô, seu, siô, sô; nhá, seá, sea, sá.

Análises variacionistas mostram que diferentes realizações fonéticas de senhor estão em competição, embora não em todos os séculos nem em todos os contextos sintáticos. Moura (2004) verifica que as variantes senhor e sô coocorrem em contextos mais restritos, isto é, aqueles em que as demais formas não ocorrem. Comparem-se as ocorrências em (4): 
(4) a. Jogue aí, sô!

b. Jogue aí, senbor!

c. Jogue aí, *sinbô/*nhô!

Ramos (2011a) mostra que senbor e você também são variantes, referindo-se ao pai em diálogos entre pai e filho. Senbor é a variante favorecida se a relação familiar é não igualitária. Esse estudo confirma a descrição de senbor como uma forma indicativa de distância social (CINTRA, 1972) ou forma de cortesia (SILVA, 2011). A contribuição desses estudos é mostrar que a ocorrência de senbor e sô é frequente e sistemática na língua. Um levantamento das ocorrências destes itens em textos dos sécs. XVI a XX, disponibilizados no Corpus do Português (DAVIES \& FERREIRA, 2006) permitiu registrar a presença de senbor em todos os séculos e de sô apenas no séc. XX. Esses resultados, juntamente com os de variação, indicam que, do ponto de vista diacrônico, senbor e sô retratam uma mudança linguística (RAMOS, 2009).

\section{Gramaticalização de pronomes}

Lehmann (2002, p. 35) refere-se à pronominalização de modo genérico: "nomes podem ser gramaticalizados como pronomes", acrescentando que a fonte de pronomes de segunda pessoa são geralmente nomes sociais. Esse parece ser o caso do item senbor, por ter sido originariamente um título e hoje referirse ao interlocutor, sendo por isso um pronome de segunda pessoa. Senbor designava inicialmente filho mais velho de proprietários de terra, não sendo ainda o item senbor usado como forma de tratamento. Posteriormente o título de senbor também foi atribuído a nobres e fidalgos, devido à posse de terras que era tida como privilégio. Tal situação demarca distanciamento social entre os interlocutores. Senbor, enquanto título, foi um nome, mais exatamente, uma expressão honorífica. 
Mas como nomes passam a pronomes? Abordagens formais do (epi)fenômeno de gramaticalização permitem descrever a formação de pronomes como resultado de reanálise. Roberts \& Roussou (2003) exemplificam casos em que um $\mathrm{DP}^{3}$ em posição de especificador é reanalisado como núcleo. Gelderen (2006) implementa essa proposta e argumenta que a reanálise como núcleo seria, de fato, um princípio gramatical, que, ao lado de outros três, tornariam a gramaticalização uma parte da Gramática Universal. Neste artigo, vamos retomar os princípios formulados por Gelderen (2006) e propor, a partir do estudo diacrônico do item senhor, um detalhamento da reanálise em que uma expressão honorífica veio a se tornar um pronome.

Gelderen (2006) argumenta que a gramaticalização constitui fonte de inovação linguística que faria parte da Gramática Universal na medida em que incluiria três princípios:

(5) a. Head Preference Principle (HPP): quando possível, seja um núcleo, e não um sintagma (GELDEREN, 2006, p. 6);

b. Late Merge Principle (LMP): compor o mais tarde possível (GELDEREN, 2006, p. 10);

c. Specifier Incorporation Principle (SIP): quando possível, seja um especificador e não um adjunto (GELDEREN, 2006, p. 15).

A cadeia de mudanças teria o seguinte formato:

(6) a. Head $>$ higher Head $>$ zero.

b. Adjunct $>$ Spec $>$ Head $>$ zero.

c. Phrase $>$ (GELDEREN, 2006, p. 34).

A mudança em (6a) seria a seguinte: o núcleo de uma categoria seria reanalisado como núcleo de uma categoria mais

${ }^{3} \mathrm{DP}=$ Determiner Phrase. 
alta. A mudança em (6b) mostra que um adjunto (via SIP) ou um sintagma mais baixo (via LMP) pode ser reanalisado como especificador, depois do que o especificador é reanalisado como núcleo (via HPP).

Dentro deste quadro, como configurar a mudança descrita em (1), em relação a senhor? Em outras palavras, como demonstrar o processo pelo qual um nome se tornou um pronome? Para chegarmos a uma resposta, um caminho seria demonstrar que senbor passou de adjunto a especificador, e de especificador a núcleo. Outro ponto a ser demonstrado é que, no processo de aquisição, a criança seja exposta a um amplo input de estruturas que provêm evidências de que sintagmas plenos possam ser analisados como tal. Conforme assinala Gelderen (2004, p. 4), essa seria uma etapa necessária. A mesma autora acrescenta que nomes em posições argumentais não são núcleos, pois sempre contêm determinante (D), e acrescenta que nomes puros ocorrem como adverbiais, predicativos e vocativos (GELDEREN, 2004, p. 187).

Em relação a senbor, é muito frequente sua ocorrência em vocativos, conforme assinalam Alkmim (2001), Alkmim \& Moreira (2005) e Moreira \& Alkmim (no prelo). Em seu estudo diacrônico, a partir de peças de teatro escritas por autores brasileiros, Moreira \& Alkmim (no prelo) formulam a seguinte hipótese:

a mudança de posição do vocativo na sentença configuraria mudanças gramaticais, tendo favorecido a gramaticalização do item senhor nessa posição e a sua consequente perda de conteúdo semântico e fônico.

Embora as autoras não justifiquem teoricamente essa correlação nem apresentem um estudo quantitativo da forma reduzida conforme a posição do vocativo no eixo do tempo e se restrinjam à apresentação de um estudo quantitativo da distribuição de vocativos conforme sua posição na sentença, a hipótese formulada é interessante, se analisada sob o ponto de vista de um tratamento formal da gramaticalização. Se tivermos em conta que o vocativo constitui o locus em que nomes ocorrem sem determinante, as 
autoras, ao chamar a atenção para uma configuração de sentença especial [oração+vocativo], acabam por ressaltar uma função sintática relevante. A nosso ver, a ocorrência de senbor como vocativo, à esquerda, à direita ou no meio da oração, teria sido o gatilho para a reanálise do nome como pronome.

Em vista disso, apresentamos na próxima seção, um estudo sobre as ocorrências de senbor em vocativos. Vamos utilizar o mesmo corpus utilizado por Moreira \& Alkmim, que nos foi gentilmente cedido por Moreira. Em seguida, analisamos dados provenientes de outros corpora, sem nos restringirmos a vocativos.

\section{Análise de dados de corpora}

Nesta seção serão comparadas quantitativa e/ou qualitativamente ocorrências extraídas de três corpora.

O primeiro corpus compõe-se de peças de teatro dos sécs. XIX e XX, cedido por Moreira, conforme mencionamos. Foram encontradas 165 ocorrências de senbor, distribuídas em dois momentos de tempo: primeira metade de séc. XIX e primeira metade do séc. XX. A Tabela 1 apresenta o número e porcentagem das ocorrências de senbor conforme o tipo do sintagma na posição de vocativo: se isoladas, como em (7), ou se seguidas e/ou precedidas de algum material, como em (8). Para esse levantamento estamos considerando, indistintamente, os vocativos à direita, à esquerda ou mediais à sentença.

(7) Não fallemos nisso, senbor. (Séc. XIX)

(8) São modos de julgar, meu senhor; nem todos enxergam o que olham. (Séc. XX) 
TABELA 1

Ocorrências de senhor em vocativos em dois períodos de tempo

\begin{tabular}{l|r|r}
\hline Vocativo & Séc. XIX & Séc. XX \\
\hline senhor & $58(63 \%)$ & $56(76 \%)$ \\
$(X)$ senhor $(X)$ & $34(37 \%)$ & $17(24 \%)$ \\
\hline Total & $92(100 \%)$ & $73(100 \%)$ \\
\hline
\end{tabular}

A Tabela 1 mostra ter havido, no eixo do tempo, um número crescente de ocorrências de senhor isoladamente no vocativo, indicando seu estatuto de núcleo. Não registramos ocorrências foneticamente reduzidas nesse primeiro corpus.

O segundo corpus compõe-se de diálogos em balcão de atendimento de órgão público (BATISTA, 2008), referido aqui como DBA, representativo de língua falada do século XXI. Nesse corpus, são documentadas formas plenas e fonologicamente reduzidas. Nesses diálogos, $\mathrm{o}$ atendente trata com cortesia o reclamante, que geralmente é uma pessoa idosa e de pouca instrução. A Tabela 2 abaixo mostra as ocorrências de uso de senhor e sô, sendo aqui consideradas todas as funções sentenciais, não se restringindo a vocativos, tal como na tabela anterior:

\section{TABELA 2}

Ocorrências das formas plenas e reduzidas no PB do século XXI

\begin{tabular}{l|c}
\hline Formas & Séc. XXI \\
\hline o senhor & $185(94,8 \%)$ \\
senbor X & - \\
senbor & - \\
sô & $10(5,2 \%)$ \\
\hline Total & $195(100 \%)$ \\
\hline
\end{tabular}

$O$ item senhor faz referência direta ao interlocutor, sendo flexionado em gênero conforme o sexo do falante. Vejam-se os diálogos (9) e (10), em que as ocorrências estão em posições argumentais, sempre precedidas de artigo: 
(9) A: A senbora quer a poda da árvore?

B: Sim.

(10) e aqui é só para o senbor não esquecer. Assina a carta para mim.

A boa formação das sentenças (9') e (10'), de nossa autoria, mostra que pronome você tem a mesma distribuição sintagmática de senbor. A escolha por senbor/senbora não decorre de exigências estruturais. ${ }^{4}$

(9') A: Você quer a poda da árvore?

B: Sim.

(10') e aqui é só para você não esquecer. Assina a carta para mim.

A comparação do número de ocorrências de senhor e você nesse corpus mostra serem ambas bem frequentes, respectivamente, 206 e 172 ocorrências.

Consideremos agora as ocorrências foneticamente reduzidas:

(11) Deus abençoa... tô sem dinheiro, sô...

(12) (...) por que lá é o seguinte, sô, (...).

(13) O negócio tá bravo, sô!

Todas as 10 ocorrências de forma reduzida se deram em função de vocativo. Em nenhuma houve material algum nem à direita nem à esquerda.

Embora informações provenientes de análise de corpora sempre sejam limitadas e parciais, pois, como se sabe, a ausência

\footnotetext{
${ }^{4} \mathrm{O}$ pronome senhor é indicativo de cortesia social e teria possivelmente um traço [+formal] ou [+honorífico] (RAMOS, 2011b).
} 
de uma construção ou item não implica sua má formação, é importante ter em conta que, nesse corpus sincrônico, não houve ocorrências de senbor seguido de qualquer material, apenas $o$ senbor $(94,8 \%)$ e sô $(5,2 \%)$. Ambas referindo-se diretamente ao interlocutor, no caso, pronomes de segunda pessoa. Quanto à função sintática, o senbor ocorre em posições argumentais e sô em vocativos.

O terceiro corpus compõe-se de entrevistas sociolinguísticas (MOTA, 2011), cujos informantes são naturais de Lontra (MG), referido aqui como CNM. Não apresentaremos aqui o estudo quantitativo das variantes, apenas vamos registrar um tipo de ocorrência, que não havia sido encontrado no corpus de diálogos em balcão de atendimento: trata-se da ocorrência de sô em posição argumental, desacompanhada de qualquer outro material.

(14) E as coisa que sô planta na roça sô traz para vender em Lontra?

(15) De que matéria, sô sabe?

Nesta seção pudemos mostrar ser relativamente alta a frequência de senbor, sendo esta semelhante à do pronome você. Mostramos também a variação entre senbor e sô em posições argumentais. Outro resultado foi perceber que, no eixo temporal, o surgimento de sô é posterior ao de senbor. Pudemos verificar uma tendência de uso de senbor sem adjuntos e também de redução fonética preferencialmente na função de vocativo. $O$ fato de essa função permitir a ocorrência de sintagmas nominais sem determinante certamente favoreceu a formação inputs em que senbor foi reconhecido como núcleo. Esse passo parece ter constituído uma etapa relevante na reanálise do nome, indicador de título honorífico, a pronome de cortesia no PB. 


\section{O percurso de adjunto a núcleo}

Retomemos aqui os princípios SIP (Specifier Incorporation Principle) e HPP (Head Preference Principle) assim formulados por Gelderen (2006, p. 15-16), respectivamente: quando possível, seja um especificador e não um adjunto; e quando possível, seja um núcleo, e não um sintagma. Levando em conta esses princípios, o percurso em análise aqui poderia ser assim descrito:

(16) Adjunto $>$ especificador $>$ núcleo nominal $>$ núcleo de determinante

Em (17), senhor (flexionado no feminino) se realiza como adjunto:

(17) A senhora duquesa deseja alguma coisa?

Veja-se que a inserção de um adjetivo não torna o sintagma mal formado.

(18) a. A gentil e honesta senhora duquesa deseja alguma coisa?

b. A bela e gentil senhora duquesa.

c. A senhora e bela duquesa.

O núcleo do sintagma nominal seria o nome duquesa; senbora seria um aposto. ${ }^{5}$ Conforme vimos, no eixo do tempo, os sintagmas contendo senhor deixam de ocorrer com outros elementos. A relação entre o artigo e o item senbor se reestrutura, e o sintagma nominal deixa de permitir adjetivos, como em (2B"'). Além disso, o artigo deixa de poder ser substituído por demonstrativos. Essa rigidez pode ser analisada como resultante de uma reanálise, que fez com que senhor deixasse de ser adjunto e passasse a ser núcleo. Uma consequência dessa reanálise foi a realização sô, como em (11) a (15).

\footnotetext{
${ }^{5}$ Esta análise, entretanto, admite dúvidas. Tal como assinala Móia (1993, p. 44), em "A Batalha de Austerlitz foi ganha pelo famoso general Napoleão, é discutível que $[\ldots]$ o nome próprio seja o núcleo nominal e o nome general ou pirata $o$ aposto (e não o inverso).".
} 


\section{Conclusões}

Neste artigo foram apresentados os resultados de análises sincrônicas e diacrônicas do item senhor. Argumentamos que este item tem, no estágio atual da língua, o estatuto de pronome. As diferentes realizações fonológicas do item documentam um processo de pronominalização. Do ponto de vista formal, tem-se um percurso em que um sintagma nominal foi reanalisado como núcleo. Argumentamos que essas reanálises manifestam dois princípios, a saber, SIP (Specifier Incorporation Principle) e HPP (Head Preference Principle) (GELDEREN, 2006), princípios da Gramática Universal, motivados por razões de economia. Vista sob o ponto de vista formal, a cline senhor $>\ldots>$ sô mostra a gramaticalização de um nome social/título a pronome. A impossibilidade de ocorrência de artigo com sô constitui uma evidência da reanálise $\mathrm{N}>\mathrm{D}$, uma vez que esse item ocorre na posição de sujeito e rejeita artigo defindo. A análise de corpora permitiu identificar que esse processo se desenvolveu nos últimos dois séculos no português e que a ocorrência do item na posição sintática de vocativo favoreceu a reanálise sintagma nominal > núcleo nominal, confirmando a importância dos vocativos no processo de pronominalização.

\section{Referências}

ALKMIM, M. G. R. Negativas sentenciais no dialeto mineiro: uma abordagem variacionista. 2001. $102 \mathrm{f}$. Tese (Doutorado) - Faculdade de Letras, Universidade Federal de Minas Gerais, Belo Horizonte, 2001.

ALKMIM, M. A.; MOREIRA, J. C. O vocativo na língua coloquial de Minas Gerais no século XIX e XX: uma abordagem variacionista. 2005. $102 \mathrm{f}$. Monografia (Bacharelado) -Instituto de Ciências Humanas e Sociais, Universidade Federal de Ouro Preto, Mariana, 2005.

ALKMIM, M. A.; MOREIRA, J. Corpus constituído de peças de teatro escritas por autores mineiros no século XIX e XX. Ouro Preto, 2011. (Inédito). 
AMARAL, A. O dialeto caipira. São Paulo/Brasília: Hucitec/INL, 1982.

BATISTA, H. Corpus de diálogos em balcão de atendimento de órgão público (19.600 palavras, século XXI). Belo Horizonte, 2008. (Inédito).

BIDERMAN, M. T. C. Formas de tratamento e estruturas sociais. ALFA, Araraquara, n. 18-19, p. 339-382, 1972-1973.

BRESNAN, J. The emergence of the unmarked pronoun. In: LEGENDRE, G.; GRIMSHAW, J.; VIKNER, S. (Ed.) Optimality-theoretic syntax. Stanford: The MIT Press, 2001. p. 113-142,. Disponível em: < http://wwwlfg.stanford.edu/bresnan/download.html >. Acesso em: 29 set. 2011.

CARVALHO, D. S. A estrutura interna dos pronomes pessoais em português brasileiro. 2008. Tese (Doutorado em Linguística) Faculdade de Letras, Universidade Federal de Alagoas, Maceió. 2008.

CINTRA, L. F. L. Sobre as formas de tratamento na língua portuguesa. Lisboa: Horizonte, 1972.

DAVIES, M.; FERREIRA, M. Corpus do português (45 milhões de palavras, séc. XIV-XX). 2006. Disponível em: <http:// www.corpusdoportugues. org >. Acesso em: 29 set. 2011.

GELDEREN, E. Principles and parameters in change. Amsterdam: John Benjamins, 2004.

GELDEREN, E. Economy of merge and grammaticalization: two steps in the evolution of language. 2006. Disponível em: <www.public.asu. edu/ gelderen/elly.htm $>$. Acesso em: 29 set. 2011.

HARLEY, H.; RITTER, E. Person and number in pronouns: a feature geometric analysis. Language, n. 78, p. 482-526, 2002.

HEAD, B. F Respect Degrees in pronominal reference. In: GREENBERG, J. (Ed.) Universals of buman language. Cambridge: Cambridge University Press, 1976. V. 3.

ILARI, R.; FRANCHI, C.; NEVES, M. H. M.; POSSENTI, S. Os pronomes pessoais do português: roteiro para análise. In: CASTILHO, A. T.; BASILIO, M. Gramática do português falado IV: estudos descritivos. Campinas: Ed. Unicamp/FAPESP, 1996. p. 79-166.

LEHMANN, C. Thoughts on grammaticalization. Munich: Lincom Europa, 1995[1982]. Disponível em: <http://pt.scribd.com/doc/ 24853253/Thoughts-on-grammaticalization-Christian-Lehmann $>$. 2002. Acesso em: 11 nov. 2011. 
MÓIA, T. Aspectos da modificação de estruturas nominais. Discursos, São Paulo, n. 4, p. 37-63, 1993. Disponível em: <www.clul.ul.pt/files/ telmo_moia/tmoia_discursos4.pdf>. Acesso em: 17 set. 2011.

MOREIRA, J. C.; ALKMIM, M. G. R. Senbor e sô em vocativos. In: RAMOS, J.; COELHO, S. Português brasileiro não-padrão: ensaios gramaticais. Campinas: Mercado de Letras, (no prelo).

MOTA, M. A. Corpus constituído de 15 entrevistas sociolinguísticas do século $X X I$. Lontra, 2011. (Inédito).

MOURA, L. Redução fonológica do item senhor e seu estatuto sintático. 2004. $154 \mathrm{f}$. Monografia (Bacharelado) - Faculdade de Letras, Universidade Federal de Minas Gerais, Belo Horizonte, 2004.

NOGUCHI, T. Two types of pronouns and variable binding. Language, n. 73, p. 770-797, 1997.

POSTAL, P. On so-called "pronouns" in English. In: REIBEL, D. A.; SCHANE, S. A. (Ed.). Modern studies in English: readings in transformational grammar. Englewood Cliffs/New Jersey: Prentice Hall, 1969.

RAMOS, J. Senhor: um novo pronome? Salvador, 2009. (Comunicação apresentada no ROSAE: I Congresso Internacional de Linguística Histórica, realizado em Salvador, na Universidade Federal da Bahia, no período de 26 a 29 de julho de 2009).

RAMOS, J. Tratamento na díade pai e filho: uso de você e senbor. In: COUTO, L. R.; LOPES, C. R. S. As formas de tratamento em português e em espanbol: variação, mudança e funções conversacionais. Niterói: Ed. UFF, 2011a. p. 289-302.

RAMOS, J. Gramaticalização do nome senhor e o traço bonorífico. Uberlândia, 2011b. (Comunicação apresentada no III Simpósio Internacional de Letras e Linguística, realizado em Uberlândia, na Universidade Federal de Uberlândia, no período de 23 a 25 de novembro de 2011).

ROBERTS, I.; ROUSSOU, A. Syntactic change: a minimalist approach to grammaticalization. Cambridge: Cambridge University Press, 2003.

SAID ALI, M. De "eu" e "tu" a majestade: tratamento de familiaridade e reverência. Revista da Cultura, Rio de Janeiro, v. 5, n. 129, p. 275, 1937. 
SAID ALI, M. Os pronomes: espécies, formas e significação. In:

Gramática Histórica da Língua Portuguesa. 7. ed. Rio de Janeiro: Melhoramentos, 1971.

SIEWIERSKA, A. Person. Cambridge: Cambridge University Press, 2004. SILVA, L. A. O senhor y você: formas de tratamento, cortesía y diversidad cultural en portugués. In: COUTO, L. R.; LOPES, C. R. S. As formas de tratamento em português e em espanbol: variação, mudança e funções conversacionais. Niterói: Ed. UFF, 2011. p. 303-314.

Recebido para publicação em 25 de outubro de 2011. Aprovado em 23 de novembro de 2011. 